\title{
Japanese Orthopaedic Association Cervical Myelopathy Evaluation Questionnaire as an outcome measure for ossification of posterior longitudinal ligament patients in East Asia: an investigation of reliability, validity, and responsiveness
}

\author{
Shuyang $\mathrm{Li}^{1 \#}$, Joe Kodama ${ }^{2 \#}$, Leixin $\mathrm{Wei}^{3 \#}$, Tingkui $\mathrm{Wu}^{4 \#}$, Hiroyasu Fujiwara ${ }^{5}$, Yukitaka Nagamoto ${ }^{6}$, \\ Lee A. Tan ${ }^{7}$, Yanbin Zhao ${ }^{1}$, Fengshan Zhang ${ }^{1}$, Shengfa Pan ${ }^{1}$, Yu Sun ${ }^{1}$, Feifei Zhou ${ }^{1}$, Takashi Kaito ${ }^{2}$, Peng \\ $\mathrm{Cao}^{3}$, Beiyu Wang ${ }^{4}$, Xiaoguang Liu ${ }^{1,8}$
}

${ }^{1}$ Department of Orthopedics, Peking University Third Hospital, Peking University, Beijing, China; ${ }^{2}$ Department of Orthopaedic Surgery, Osaka University Graduate School of Medicine, Suita, Japan; ${ }^{3}$ Department of Orthopaedic Surgery, Changzheng Hospital, Second Military Medical University, Shanghai, China; ${ }^{4}$ Department of Orthopedic Surgery, West China Hospital, Sichuan University, Chengdu, China; ${ }^{5}$ Department of Orthopaedic Surgery, National Hospital Organization Osaka Minami Medical Center, Osaka, Japan; ${ }^{6}$ Department of Orthopaedic Surgery, Osaka Rosai Hospital, Osaka, Japan; ${ }^{7}$ Department of Neurosurgery, UCSF Medical Center, San Francisco, CA, USA; ${ }^{8}$ Department of Orthopedics, Beijing Jishuitan Hospital, Beijing, China

Contributions: (I) Conception and design: S Li, J Kodama, L Wei, T Wu, P Cao, T Kaito, B Wang, X Liu, F Zhou; (II) Administrative support: X Liu; (III) Provision of study materials or patients: H Fujiwara, Y Nagamoto, Y Zhao, F Zhang, S Pan, Y Sun, P Cao, T Kaito, B Wang, X Liu, F Zhou; (IV) Collection and assembly of data: S Li, J Kodama, L Wei, T Wu; (V) Data analysis and interpretation: S Li, F Zhou; (VI) Manuscript writing: All authors; (VII) Final approval of manuscript: All authors.

\#These authors contributed equally to this work.

Correspondence to: Feifei Zhou, MD. Department of Orthopedics, Peking University Third Hospital, Peking University, Beijing, China. Email: orthozhou@163.com; Takashi Kaito, MD. Department of Orthopaedic Surgery, Osaka University Graduate School of Medicine, Suita, Japan. Email: takashikaito@ort.med.osaka-u.ac.jp; Peng Cao, MD. Department of Orthopaedic Surgery, Changzheng Hospital, Second Military Medical University, Shanghai, China. Email: mdpinocao@163.com; Beiyu Wang, MD. Department of Orthopedic Surgery, West China Hospital, Sichuan University, Chengdu, China. Email: dove-baker@163.com; Xiaoguang Liu, MD. Department of Orthopedics, Beijing Jishuitan Hospital, Beijing, China. Email: xgliudoctor@163.com.

Background: The surgical outcomes of individual patient with ossification of the posterior longitudinal ligament (OPLL) can vary depending on various patient-related factors. Japanese Orthopaedic Association Cervical Myelopathy Evaluation Questionnaire (JOACMEQ) is a well-developed tool for outcome measurement and considers both disease-specific and general health aspects. This study aimed to investigate the reliability, validity, and responsiveness of the JOACMEQ in patients with OPLL in mainland China and to compare post-operative outcomes of OPLL patients between mainland China and Japan.

Methods: This multicenter trial was performed between July 2009 and June 2019. The procedure for the JOACMEQ translation followed Beaton's guidelines. All patients enrolled were diagnosed with OPLL and had completed the JOACMEQ, the modified Japanese Orthopaedic Association (mJOA) scale, and the 36Item Short Form Health Survey (SF-36) before and after surgery. The reliability (Cronbach's $\alpha$ and Pearson's correlation), construct validity (factor analysis), concurrent validity (Spearman's correlation with SF-36) and responsiveness (effect sizes) of JOACMEQ were evaluated. A mixed-model analytic approach was used to analyze differences in postoperative outcomes between the 2 countries.

Results: Ninety-one patients from mainland China and ninety-one patients from Japan were recruited. JOACMEQ showed satisfactory internal consistency (Cronbach's $\alpha=0.75$ ). In test-retest reliability evaluation, except for the bladder function domain, the JOACMEQ domains had good test-retest reliability (0.89-0.96). In factor analysis, most of the items (19/24) were well clustered. Regarding clinical validity, all 5 domains were found to have moderate correlations with the physical component summary (PCS) of SF-36 (r=0.25- 
0.50), and the bladder function and quality of life domains also had moderate correlations $(\mathrm{r}=0.25-0.50)$ with the mental component summary (MCS) of SF-36. JOACMEQ showed a variable responsiveness in different domains (effect size $=0.17-0.84$; standardized response means $=0.15-0.85$ ). Regarding postoperative improvements in the JOACMEQ score, mixed-model analysis revealed a significant difference in the quality of life domain between Chinese and Japanese patients $(16.0 \pm 18.7$ vs. $7.8 \pm 17.7, \mathrm{P}<0.05)$.

Conclusions: JOACMEQ generally shows good reliability, good validity and mild responsiveness, and can identify the post-operative improvements in patients with OPLL in mainland China. Chinese OPLL patients showed a significantly larger improvement in postoperative quality of life compared to their Japanese counterparts.

Keywords: Ossification of the posterior longitudinal ligament (OPLL); Japanese Orthopaedic Association Cervical Myelopathy Evaluation Questionnaire (JOACMEQ); cervical spondylotic myelopathy (CSM); treatment outcome; post-operative functional recovery

Submitted 18 Dec, 2020. Accepted for publication May 04, 2021.

doi: $10.21037 /$ atm-20-8064

View this article at: http://dx.doi.org/10.21037/atm-20-8064

\section{Introduction}

Ossification of the posterior longitudinal ligament (OPLL) results from pathologic calcification of the PLL, and can lead to spinal cord compression and neurological deterioration. It is much more prevalent among East Asian populations than non-Asian populations $(1,2)$. The most commonly used classification for OPLL was developed by the Investigation Committee on OPLL of the Japanese Ministry of Health and Welfare. On the basis of patients' radiographic evaluations, such as neutral lateral radiography and computed tomography (CT), the classification divides OPLL into 4 types: continuous, segmental, mixed, and other. However, it is still difficult to determine the severity of the symptoms caused by OPLL. As a clinical syndrome, OPLL can lead to various neurological dysfunctions arising from long-term cervical spinal cord compression (3-5). OPLL generally progresses slowly over years and often involves multiple segments, which makes early diagnosis challenging, as many patients do not seek medical attention until complexity symptoms are apparent $(6,7)$. In symptomatic cases, surgical treatment is considered to be the most effective way to prevent disease progression $(3-5,8)$.

Despite surgical outcomes for OPLL generally being favorable, the outcomes of individual patients may vary depending on various factors relating to the patient and the surgical approach (9). Therefore, standardized outcome measures are needed to quantify the severity of disease, document the efficacy of surgical intervention, and evaluate the effect of treatment on patients' overall quality of life (QOL). The modified Japanese Orthopaedic Association (mJOA) scale is one of the most commonly used rating systems for assessing the severity of cervical myelopathy, however, it does not include domains on general healthy status, QOL, or patient satisfaction. Therefore, other QOL measurement tools, such as the 36-Item Short Form Health Survey (SF-36), are commonly used in conjunction with the mJOA to evaluate patients' general health and quality of life based on self-reported outcome measures. However, after a long clinical course, the combination of the mJOA and SF36 has its own limitations. First, the completion of many different scales is time-consuming for patients. Second, the 2 scales contain some similar questions, which means that the overlap might be confusing and result in an unexpected decrease in the facticity of the evaluation results. Moreover, the decline in QOL caused by some common symptoms of OPLL, such as bladder dysfunction, is not within the scope of the SF-36.

A comprehensive clinical assessment tool should be concise, and take both disease-specific evaluation and general health evaluation into consideration. In 2007, a more comprehensive outcome measure, the Japanese Orthopaedic Association Cervical Myelopathy Evaluation Questionnaire (JOACMEQ), was introduced to quantify the severity of cervical myelopathy across 5 different domains represented by 5 intuitive numerical scores (10). The JOACMEQ has been demonstrated to have good validity and reliability, and has strong correlations with 
other commonly used neck pain, cervical function, and QOL questionnaires in the Japanese patient population $(11,12)$. However, to the best of our knowledge, no study has examined the reliability, validity and responsiveness of JOACMEQ in mainland China specifically in patients with OPLL.

Patients with symptomatic OPLL who present with myelopathic symptoms typically require surgery to prevent symptom progression. Several studies have demonstrated that surgery can obtain satisfactory results for the majority of Chinese and Japanese patients, with an acceptable complications rate (13-15). Numerous studies have suggested that there are geographical differences in both disease prevalence and clinical prognosis in a variety of medical conditions (16). Moreover, differences in cultural background can affect patients' cognition of OPLL, which can further impact their QOL. However, no previous study has compared outcomes between surgically treated patients with OPLL in mainland China and Japan.

In the present research, we conducted a prospective, multicenter, controlled trial between China and Japan. We aim to establish an appropriate and reliable method for the assessment of patients with OPLL presenting neurological manifestation and related deterioration of health and QOL. To the best of our knowledge, this is the first study to specifically compare surgical outcomes between Chinese and Japanese patients who underwent surgery for OPLL.

We present the following article in accordance with the TREND reporting checklist (available at http://dx.doi. org/10.21037/atm-20-8064).

\section{Methods}

\section{Study design}

This study was a prospective multicenter controlled trial between 3 institutions in mainland China (in Shanghai, Sichuan, and Beijing) and 3 institutions in Japan (in Osaka). This study is registered in Chinese Clinical Trial Registry (Registration \#: ChiCTR1800015459). All the patients had a diagnosis of OPLL based on disease history, physical, and imaging examination, and surgical treatment received between July 2009 and June 2019. Each patient completed all necessary evaluations, including the mJOA, SF-36, and JOACMEQ questionnaires, preoperatively and at the 6-month postoperative follow-up. A Simplified Chinese version of the JOACMEQ was provided to a subgroup of patients at 1 of the Chinese institutions, and these patients were evaluated twice before surgery ( 1 week apart, in the outpatient clinic and on the ward, respectively). The exclusion criteria for the study included recent cervical spine trauma, poorly controlled preoperative medical comorbidities (i.e., serious systemic infection, coronary heart disease and diabetes), or a previous history of cervical spinal operations, infection, or neoplasm.

\section{Scales and translation}

The mJOA was released by the Japanese Orthopaedic Association (JOA) in 1994, and was found to have a good correlation with the original JOA for the evaluation of cervical spondylotic myelopathy (CSM) (17). It is now widely used for spinal cord function evaluation of patients with CSM worldwide and is considered as one of the "gold standards" of neurological evaluation, including in China. The SF-36 questionnaire, which was developed by the American Institute of Health in Boston, is used as a measure of QOL among various populations, including the healthy population and patients with different diseases. The reliability and validity of the SF-36 has also been proven among patients with CSM $(18,19)$. The JOACMEQ was developed by the JOA, and was first published in 2007 . The procedure for JOACMEQ translation followed the guidelines of Beaton et al. (20).

\section{Estimation of sample size and power}

Sample size estimation was conducted for the JOACEMQ score comparison of patients from the 2 countries. The sample size was calculated using PASS 11, and was based on the postoperative recovery rate of patients with OPLL reported in the literature. A sample size of 104 in each group was required to achieve $80 \%$ power to detect a difference of 9.0 between the null hypothesis that both group means are 63 and the alternative hypothesis that the mean of group 2 is 55 , with estimated group standard deviations of 28.0 and 17.0 and with a significance level (alpha) of 0.05 using a 2 -sided 2-sample $t$-test. Anticipating an expulsion rate of $20 \%$, we set the sample size as 150 for each group.

\section{Statistical analysis}

SPSS 19.0 statistical package was used to establish a database and to conduct data management and analysis. 
Table 1 Internal consistency and test-retest reliability of JOACEMQ subscale

\begin{tabular}{lccccc}
\hline Domain & Item & Cronbach's $\alpha$ & First test & Retest & Correlation coefficient \\
\hline Cervical spine function & 4 & 0.73 & $82.7 \pm 23.5$ & $84.0 \pm 24.0$ & 0.89 \\
Upper extremity function & 3 & 0.64 & $84.9 \pm 19.6$ & $84.5 \pm 24.1$ & 0.90 \\
Lower extremity function & 5 & 0.63 & $71.8 \pm 30.0$ & $75.1 \pm 27.4$ & 0.96 \\
Bladder function & 4 & 0.78 & $79.0 \pm 14.9$ & $76.7 \pm 18.5$ & 0.54 \\
Quality of life & 8 & 0.70 & $51.0 \pm 23.7$ & $53.2 \pm 21.7$ & 0.93 \\
Total & 24 & 0.75 & - & - & - \\
\hline
\end{tabular}

*, we count 'Total' for the use of the calculation of Cronbach's $\alpha$ co-efficient (here 'Total' means all categories of JOACMEQ). During the clinical application, we don't use total score for evaluation, and it's meaningless to add scores of each item.

Internal consistency reliability was measured by Cronbach's $\alpha$, with a value $>0.70$ representing acceptable reliability (21). Test-retest reliability was assessed based on the correlation between the 1-week test-retest results. An exploratory and confirmed factor analysis (principal component analysis with varimax rotation) was carried out to investigate the correlations among the JOACMEQ questions and compare the factorial structure of the output with those defined by the original JOACMEQ to confirm the construct validity. Concurrent validity (clinical validity) was assessed by calculating Spearman's correlation coefficient to determine the correlation between the JOACMEQ individual domain scores against the SF-36. Internal responsiveness, which attempts to characterize a scale's ability to detect change over a prespecified time frame, was determined based on effect size (ES) and standardized response means (SRM). General rules for estimating the magnitude of the ES or SRM were as follows: $<0.20$, trivial effect; $0.20-0.50$, small effect; 0.50 0.80 , moderate effect; and $>0.80$, large effect (22).

Preoperatively, and at each follow-up visit, patients were evaluated using the mJOA, SF-36 and JOACMEQ. A mixed-model analytic approach was adopted to evaluate differences in outcomes between the Chinese and Japanese patient cohorts 6 months postoperatively.

\section{Ethics statement}

This prospective cohort study was approved by Peking University Third Hospital Medical Science Research Ethics Committee (reference No. M2017310). The study was conducted in accordance with the Declaration of Helsinki (as revised in 2013). All the participants gave informed consent to taking part in this study.

\section{Results}

\section{Patients enrollments}

A total of 91 Chinese patients (mean age: $57.6 \pm 9.4$ years old; males/females $=53 / 38$ ) with OPLL who received surgical treatment at the 3 participating institutions in mainland China were enrolled in this prospective study. All of the patients completed every outcome measurement before the surgery and during the 6-month follow-up.

A total of 91 Japanese patients (mean age $64.9 \pm 11.8$ years old; males/females $=65 / 26$ ), from 3 hospitals in Osaka, Japan, fulfilled the inclusion criteria and were enrolled in the study. All of the patients completed the necessary pre- and postoperative measures.

\section{Reliability}

The reliability of the JOACMEQ in the patients with OPLL from mainland China was analyzed using Cronbach's $\alpha$, and the results of each domain are shown in Table 1. Based on the Nunnally criterion of 0.7 , cervical spine function (0.73), bladder function (0.78), and QOL (0.70) all exceeded the value of 0.7 . The upper extremity function (0.64) and lower extremity function (0.63) were lower than 0.7 , but still over 0.5 , indicating that the internal consistency as not weak. When the 24 questions in the JOACMEQ were considered together, Cronbach's $\alpha$ showed a value of 0.75 , suggesting satisfactory internal consistency.

A subset of 33 patients was included in evaluating test-retest reliability, including the JOACMEQ tests preoperatively, at the outpatient clinic and on the orthopedic ward. The mean score and the Pearson's correlation of each domain's first test and retest are shown in Table 1. None of the 5 domains showed a statistically significant difference 
Table 2 Results of factor analysis

\begin{tabular}{|c|c|c|c|c|c|c|}
\hline Factor & \multicolumn{3}{|c|}{ Initial eigenvalues } & \multicolumn{3}{|c|}{ Rotation sums of squared loadings } \\
\hline 2 & 2.422 & 10.484 & 41.617 & 3.930 & 16.375 & 34.090 \\
\hline 5 & 1.249 & 6.248 & 62.139 & 1.615 & 6.729 & 62.139 \\
\hline 6 & 1.080 & 5.171 & 67.310 & - & - & - \\
\hline 7 & 0.947 & 4.307 & 71.617 & - & - & - \\
\hline 11 & 0.654 & 2.296 & 84.438 & - & - & - \\
\hline 12 & 0.594 & 2.131 & 86.570 & - & - & - \\
\hline 13 & 0.506 & 2.093 & 88.662 & - & - & - \\
\hline 14 & 0.410 & 1.899 & 90.561 & - & - & - \\
\hline 15 & 0.364 & 1.695 & 92.256 & - & - & - \\
\hline 16 & 0.346 & 1.547 & 93.803 & - & - & - \\
\hline 17 & 0.317 & 1.259 & 95.063 & - & - & - \\
\hline 23 & 0.134 & 0.526 & 99.744 & - & - & - \\
\hline 24 & 0.118 & 0.256 & 100.000 & - & - & - \\
\hline
\end{tabular}

between the first test and then the re-test. Except for the bladder function domain (Pearson's correlation $=0.54$ ), the domains all had correlation coefficients between 0.89 and 0.96 , suggesting satisfactory test-retest reliability.

\section{Validity}

After applying the Kaiser-Meyer-Olkin (KMO) statistic and Bartlett's test of sphericity (KMO $=0.70$, Bartlett's test, $\left.\chi^{2}=1,195.7, \mathrm{P}<0.05\right)$, we found that the values indicated that this data set was amenable to factor analysis. In the factor structure analysis of the scale, after releasing the scale items, principal components analysis suggested that 6 factors had an eigenvalue above 1 (Table 2). However, if the factor analysis was limited to 5 , all of the factors still had an eigenvalue above 1 (Table 2). Then, the rotated component matrix was conducted (Table 3), and most of the items were clustered and loaded for each of the 5 factors (19/24).

According to the results of the comparison between the JOACMEQ domains and the physical component summary (PCS)/mental component summary (MCS) domains of the SF-36, the concurrent validity is shown in Table 4. For the PCS, the correlations for all 5 domains were found to be moderate $(r=0.25-0.50, \mathrm{P}<0.05)$. Concerning the MCS, the 
Table 3 Rotated component matrix for the Chinese JOACMEQ

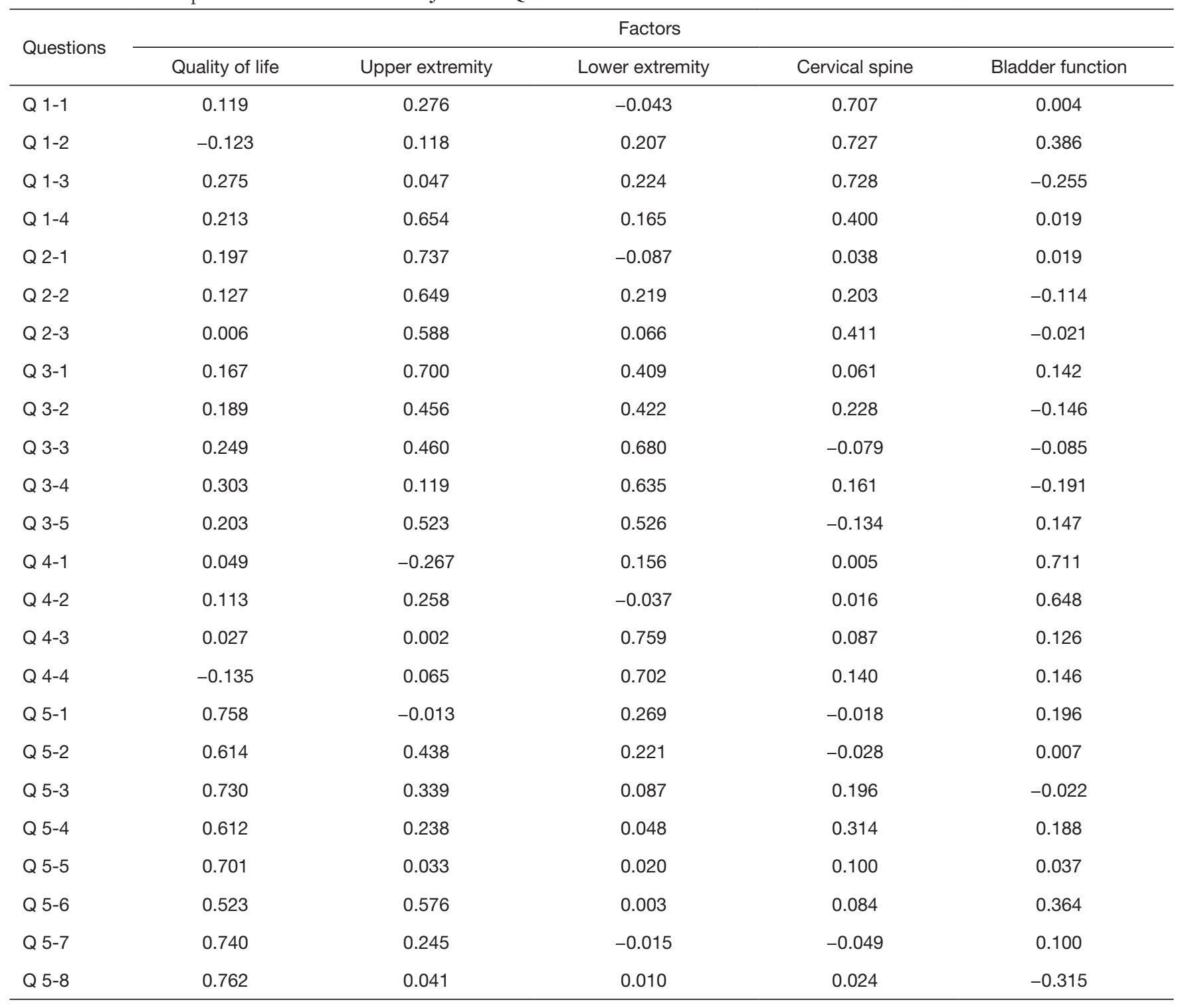

Table 4 Results of clinical validity

\begin{tabular}{lcccc}
\hline \multirow{2}{*}{ Item } & \multicolumn{2}{c}{ PCS } & & \multicolumn{1}{c}{ MCS } \\
\cline { 2 - 4 } \cline { 4 - 5 } Cervical spine function & Correlation coefficient & P value & & Correlation coefficient \\
Upper extremity function & 0.26 & 0.012 & 0.066 & 0.535 \\
Lower extremity function & 0.46 & $<0.001$ & 0.099 & 0.349 \\
Bladder function & 0.46 & $<0.001$ & 0.077 & 0.33 \\
Quality of life & 0.26 & 0.015 & 0.001 & 0.43 \\
\hline
\end{tabular}


Table 5 Internal responsiveness for each domain of the JOACMEQ

\begin{tabular}{lcl}
\hline Item & ES & SRM \\
\hline Cervical spine function & 0.17 & 0.15 \\
Upper extremity function & 0.46 & 0.37 \\
Lower extremity function & 0.41 & 0.37 \\
Bladder function & 0.42 & 0.34 \\
Quality of life & 0.84 & 0.85 \\
\hline
\end{tabular}

Table 6 Comparison of JOACMEQ post-operative changing between Chinese and Japanese patients

\begin{tabular}{|c|c|c|c|}
\hline Item & $\begin{array}{l}\text { Improvement of } \\
\text { Chinese patients }\end{array}$ & $\begin{array}{l}\text { Improvement of } \\
\text { Japanese patients }\end{array}$ & $P$ value \\
\hline $\begin{array}{l}\text { Cervical spine } \\
\text { function }\end{array}$ & $3.7 \pm 24.6$ & $1.3 \pm 27.7$ & 0.893 \\
\hline $\begin{array}{l}\text { Upper extremity } \\
\text { function }\end{array}$ & $7.2 \pm 19.6$ & $9.1 \pm 18.9$ & 0.295 \\
\hline $\begin{array}{l}\text { Lower extremity } \\
\text { function }\end{array}$ & $8.7 \pm 23.8$ & $11.5 \pm 21.3$ & 0.239 \\
\hline Bladder function & $6.5 \pm 18.9$ & $3.7 \pm 21.2$ & 0.558 \\
\hline Quality of life & $16.0 \pm 18.7$ & $7.8 \pm 17.7$ & 0.001 \\
\hline
\end{tabular}

bladder function domain and QOL domain were found to have moderate correlations $(\mathrm{r}=0.25-0.50, \mathrm{P}<0.05)$, but the correlations for the other 3 domains were not statistically significant $(\mathrm{P}>0.05)$.

\section{Responsiveness}

To evaluate the internal responsiveness of the JOACMEQ, we compared the scales completed preoperatively to those completed 6 months postoperatively. Table 5 shows the ES and SRM values of each domain. For cervical spine function, both the ES and SRM values were lower than 0.20, showing a trivial effect. The ES and SRM values of upper extremity function, lower extremity function and bladder function were between 0.20 and 0.50 , showing small effect. In QOL domain, the ES and SRM values all exceeded 0.80, suggesting satisfactory responsiveness of the JOACMEQ.

\section{Geographic comparison}

To investigate whether surgery is equally effective and safe for patients with OPLL in China and Japan, we compared the scores of mJOA and SF-36 preoperatively and 6 months after surgery between Chinese and Japanese patients. Then, each domain's improvement of JOACMEQ was calculated, and the comparisons between the improvement in patients from the 2 countries were conducted. Both countries' mJOA scores (China: $12.8 \pm 2.7$ vs. $15.3 \pm 2.1, \mathrm{P}<0.05$; Japan: $10.3 \pm 2.4$ vs. $13.9 \pm 2.3, \mathrm{P}<0.05)$, the Chinese PCS and MCS scores (PCS: $40.7 \pm 8.7$ vs. $47.5 \pm 9.1, \mathrm{P}<0.05$; MCS: $39.8 \pm 12.1$ vs. $46.5 \pm 11.8)$, and the Japanese PCS scores $(34.9 \pm 6.7$ vs. $39.9 \pm 7.8, \mathrm{P}<0.05$; MCS $36.6 \pm 13.0$ vs. $38.4 \pm 13.5$, $\mathrm{P}=0.106)$ showed significant differences pre-operatively and at 6 months after surgery. These results indicated the effectiveness and safety of surgical management for patients with OPLL in mainland China and Japan. Moreover, the degree of improvement in each domain was compared between 2 patient cohorts, and the results are summarized in Table 6. The differences in improvements of cervical spine function, upper extremity function, lower extremity function, and bladder function domains were not statistically significant $(\mathrm{P}>0.05)$. However, a significant difference was observed in the QOL domain between patients in the 2 countries $(\mathrm{P}<0.05)$.

\section{Discussion}

Since its initial introduction in 2007, the JOACMEQ has been widely used in Japan, and has demonstrated good validity, reliability, and responsiveness in Japanese patients with OPLL. It has also been shown to have a strong correlation with other widely used clinical measurement tools, including evaluations of health related QOL (HRQOL) and neck pain parameters (23-25). Outside Japan, the JOACMEQ had been validated in Hong Kong, Taiwan, Thailand and Iran (26-29). Although Yao et al. (30) conducted a study to investigate the reliability and validity of the JOACMEQ in patients with CSM in mainland China, not all the patients in the study group received surgical treatment, and the study did not consider treatment outcome. Chien et al. (26) and Cheung et al. (27) published articles on translation and psychometric testing of the JOACMEQ. They found that the psychometric properties of the Traditional Chinese version of the JOACMEQ were equal to those of the original JOACMEQ and verified the ability of the Traditional Chinese JOACMEQ in diagnostic and outcome measurement for Chinese patients with CSM in Hong Kong and Taiwan. However, there are still differences in the usage of languages, medical and social conditions, and cultural backgrounds in mainland China. 
Therefore, the purpose of the present research was to verify the reliability, validity, and responsiveness of the Simplified Chinese version of the JOACMEQ in patients with OPLL from across mainland China. We also aimed to characterize and compare patient demographics, disease severity, and surgical outcomes of OPLL in mainland China and Japan based on hospitals' data in the two countries.

In the reliability analysis, the results based on Cronbach coefficients indicated good internal consistency among the patients with OPLL, which was consistent with studies in Hong Kong and Taiwan (26,27). For the test-retest reliability analysis, except for the bladder function domain, the domains had good test-retest reliability, as indicated by Pearson's correlation. After the JOACMEQ was first published in 2007 , a test-retest reliability evaluation in patients with OPLL in Japan showed acceptable results in the 5 domains, with the kappa coefficients of all questions being above 0.4 (23). Results of patients in Taiwan also showed good test-retest reliability with the intraclass correlation coefficient (ICC) values above 0.7 ; however, among patients in Thailand, the ICC values of cervical spine function and bladder function domain were lower than 0.7 (0.63 and 0.62, respectively) (28). Our patient group had a mean age of 57.6 years old. For older patients, several comorbidities and body function degenerations, such as lower urinary tract symptoms suggestive of benign prostatic hyperplasia in males and urinary incontinence caused by pelvic floor dysfunction in females (which were not regularly asked during the medical history recording), also could affect patients' bladder function and quality of life (31-33). Patients put different particular emphasis on the response to the medical history in query in the outpatient clinic (focus on OPLL) and on the wards (for instance, affect by the questions of previous history), which could be a reason for the low Pearson's correlation value of the bladder function domain in the test-retest reliability analysis. Appropriate wording of specific questions could help patients put the focus on the dysfunctions specifically caused by OPLL or other cervical spine diseases.

In the analysis of validity, the initial factor analysis indicated that 6 factors could explain $67.3 \%$ of the variance; when limited to 5 factors, the ratio was $62.1 \%$. Most of the questions (19/24) had significantly higher correlation coefficients with the specific domains than with other domains. Chien et al. (26) obtained similar results in the construct validity analysis in patients with CSM in Taiwan, and our results were consistent with those were published in the original JOACMEQ (24). In the clinical validity analysis, the scores of cervical spine function, upper extremity function, lower extremity function domains in the JOACMEQ had correlations only with the PCS scores of the SF-36, which were specifically related to physical function. In contrast, the bladder functions and QOL domains had correlations with both the PCS and MCS scores, revealing their relationship with the physical and mental aspects of patients' lives.

In evaluating responsiveness, 2 types of assessments (ES and SRM) were used to analyze internal responsiveness, and the results detected significant effect in the QOL domain. The trivial or small effects of the other four domains, combined with the satisfactory effect of the QOL domain, indicated that in the first 6 months postoperatively, the rehabilitation of body functions may not be significant enough for patients to notice, while the alleviation of pain and numbness can greatly improve the QOL (34), reflecting the characteristics and views of symptom recovery among the OPLL population in mainland China. With a longer follow-up, the other 4 domains could show greater improvements and have larger value of ES and SRM values.

To verify the effectiveness of surgery in treating patients with OPLL in Japan and China, we used two evaluation scales that had been well verified internationally (mJOA and SF-36) and compared the preoperative and postoperative scores. Patients from both countries showed significant improvements in mJOA and PCS of SF-36 evaluations, but a difference was observed in comparison about the significance of improvement in the MCS of SF-36 and we found similar results in the comparison of the improvement in JOACMEQ score. After surgical management, a significant difference in improvement was only observed between the two countries in the QOL domain of the JOACMEQ, with the score improvement of OPLL patients in Japan being conspicuously lower than that of Chinese patients. Ohya et al. similarly found that compared with the preoperative scores, OPLL patients showed a score improvement of 8.1 in the JOACMEQ QOL domain $(44.4 \pm 18.0$ vs. $52.5 \pm 16.9)$ after a minimum 1-year follow-up (12). Oshima $e t a l$. also found that the QOL domain score only had significantly improved at 2 weeks after surgery, and decreased at 3 months after surgery to a level comparable with the preoperative results (11).

In Japan, many patients with OPLL prefer conservative treatment, and have a psychological conflict with surgical management. During a long-term follow-up study of OPLL patients in Japan, Matsunaga et al. found that almost 30\% 
of patients (36/137) who had presented with symptoms of myelopathy at the first examination opted for conservative treatment (35). Patients in Japan usually receive surgical management in their 60 s $(11,12,36,37)$ and often seek surgical treatment after a long disease progression course. Consequently, their pathology and symptoms at the time of surgical intervention are more severe, resulting in a lower improvements of postoperative scores in QOL domian. Besides the influencing factors related to disease development, patients' attitudes towards their disease also affect QOL outcomes.

OPLL is the leading cause of CSM in Japan (38), and due to its rarity outside Japan, OPLL was once referred to as "the Japanese disease" during the early stage of investigation of this disease $(39,40)$. The Japanese Ministry of Health, Labor and Wealth has classified OPLL as one of the "intractable diseases". Although an international consensus has been reached that OPLL is a global issue and not just a single-country issue, Japanese patients still have a heavier psychological burden from OPLL than patients in other countries, contributing to a pessimistic mood towards their disease and QOL. In contrast, Chinese patients are generally less familiar with OPLL. Patients with physical disabilities in China often face more difficulties and mental stigma during the disease development due to a lack of social infrastructure support. Therefore, after surgical management, the changes in the SF-36 MCS score and the JOACMEQ QOL domain score, which reflect patients' mental state, were larger than those in the Japanese cohort.

There are several limitations to this study. Although enrollment was limited to patients with a diagnosis of OPLL, the specific types of OPLL and surgical approaches were not analyzed in this study. While many research pieces have confirmed that there are no significant differences between anterior and posterior procedures $(1,2,29)$, this factor could have potentially affected the outcome measurements. Moreover, factors including age, health status, and occupation could also impact postoperative outcomes. Control variables should be considered in further investigations to explore the specific differences in outcome improvements after surgery. Secondly, the length of followup was only 6 months, and consequently, the responsiveness evaluation could not include more parameters, such as health transition item (HTI) in the SF-36, nor were factors like visual analogue scale (VAS) score and surgeon rating included. Further research with longer follow-up times should be performed to determine the properties of the JOACMEQ in patients with OPLL.

\section{Conclusions}

Compared with established clinical outcome measurement tools, the Simplified Chinese version of the JOACMEQ has satisfactory reliability, validity, and responsiveness for identifying postoperative outcome improvements in patients with OPLL from mainland China in both the physical and mental aspects. Surgical management showed good effectiveness in patients with OPLL in both China and Japan. At 6 months postoperatively, OPLL patients from mainland China displayed a greater score improvement in the QOL domain of the JOACMEQ than patients from Japan.

\section{Acknowledgments}

Funding: This work received funding from the AOSpine Asia Pacific Regional Research Project 2018 (project No. AOSAP(R) 2018-05).

\section{Footnote}

Reporting Checklist: The authors have completed the TREND reporting checklist. Available at http://dx.doi. org/10.21037/atm-20-8064

Data Sharing Statement: Available at http://dx.doi. org/10.21037/atm-20-8064

Conflicts of Interest: All authors have completed the ICMJE uniform disclosure form (available at http://dx.doi. org/10.21037/atm-20-8064). The authors have no conflicts of interest to declare.

Ethical Statement: The authors are accountable for all aspects of the work in ensuring that questions related to the accuracy or integrity of any part of the work are appropriately investigated and resolved. This prospective cohort study was approved by Peking University Third Hospital Medical Science Research Ethics Committee (reference No. M2017310). The study was conducted in accordance with the Declaration of Helsinki (as revised in 2013). All the participants gave informed consent to taking part in this study.

Open Access Statement: This is an Open Access article distributed in accordance with the Creative Commons Attribution-NonCommercial-NoDerivs 4.0 International License (CC BY-NC-ND 4.0), which permits the non- 
commercial replication and distribution of the article with the strict proviso that no changes or edits are made and the original work is properly cited (including links to both the formal publication through the relevant DOI and the license). See: https://creativecommons.org/licenses/by-nc-nd/4.0/.

\section{References}

1. Tsuyama N. Ossification of the posterior longitudinal ligament of the spine. Clin Orthop Relat Res 1984;(184):71-84.

2. Wang MY, Thambuswamy M. Ossification of the posterior longitudinal ligament in non-Asians: demographic, clinical, and radiographic findings in 43 patients. Neurosurg Focus 2011;30:E4.

3. Boody BS, Lendner M, Vaccaro AR. Ossification of the posterior longitudinal ligament in the cervical spine: a review. Int Orthop 2019;43:797-805.

4. Smith ZA, Buchanan CC, Raphael D, et al. Ossification of the posterior longitudinal ligament: pathogenesis, management, and current surgical approaches. A review. Neurosurg Focus 2011;30:E10.

5. Aljuboori Z, Boakye M. The Natural History of Cervical Spondylotic Myelopathy and Ossification of the Posterior Longitudinal Ligament: A Review Article. Cureus 2019;11:e5074.

6. Choi BW, Song KJ, Chang H. Ossification of the posterior longitudinal ligament: a review of literature. Asian Spine J 2011;5:267-76.

7. Jeon I, Cho YE. Analysis of Factors Contributing to Repeat Surgery in Multi-Segments Cervical Ossification of Posterior Longitudinal Ligament. J Korean Neurosurg Soc 2018;61:224-32.

8. Zhang J, Liang Q, Qin D, et al. The anterior versus posterior approach for the treatment of ossification of the posterior longitudinal ligament in the cervical spine: A systematic review and meta-analysis. J Spinal Cord Med 2021;44:340-9.

9. Ogawa Y, Toyama Y, Chiba K, et al. Long-term results of expansive open-door laminoplasty for ossification of the posterior longitudinal ligament of the cervical spine. J Neurosurg Spine 2004;1:168-74.

10. Fukui M, Chiba K, Kawakami M, et al. An outcome measure for patients with cervical myelopathy: Japanese Orthopaedic Association Cervical Myelopathy Evaluation Questionnaire (JOACMEQ): Part 1. J Orthop Sci 2007;12:227-40.

11. Oshima K, Iwasaki M, Sakaura H, et al. Comparison of the
Japanese orthopaedic association score and the Japanese orthopaedic association cervical myelopathy evaluation questionnaire scores: time-dependent changes in patients with cervical spondylotic myelopathy and posterior longitudinal ligament. Asian Spine J 2015;9:47-53.

12. Ohya J, Oshima Y, Oka H, et al. Patient Satisfaction with Posterior Decompression Surgery for Cervical Ossification of the Posterior Longitudinal Ligament: Prognostic Radiographic Factors and Patient-Reported Outcomes for the Effectiveness of Surgical Treatment. World Neurosurg 2016;96:272-9.

13. Chen Y, Guo Y, Lu X, et al. Surgical strategy for multilevel severe ossification of posterior longitudinal ligament in the cervical spine. J Spinal Disord Tech 2011;24:24-30.

14. Chen Y, Chen D, Wang X, et al. Anterior corpectomy and fusion for severe ossification of posterior longitudinal ligament in the cervical spine. Int Orthop 2009;33:477-82.

15. Iwasaki M, Okuda S, Miyauchi A, et al. Surgical strategy for cervical myelopathy due to ossification of the posterior longitudinal ligament: Part 2: Advantages of anterior decompression and fusion over laminoplasty. Spine (Phila Pa 1976) 2007;32:654-60.

16. Ikegawa S. Genomic study of ossification of the posterior longitudinal ligament of the spine. Proc Jpn Acad Ser B Phys Biol Sci 2014;90:405-12.

17. Kato S, Oshima Y, Oka H, et al. Comparison of the Japanese Orthopaedic Association (JOA) score and modified JOA (mJOA) score for the assessment of cervical myelopathy: a multicenter observational study. PLoS One 2015;10:e0123022.

18. Kalsi-Ryan S, Singh A, Massicotte EM, et al. Ancillary outcome measures for assessment of individuals with cervical spondylotic myelopathy. Spine (Phila Pa 1976) 2013;38:S111-22.

19. Zhang Y, Zhou F, Sun Y. Assessment of health-related quality of life using the SF-36 in Chinese cervical spondylotic myelopathy patients after surgery and its consistency with neurological function assessment: a cohort study. Health Qual Life Outcomes 2015;13:39.

20. Beaton DE, Bombardier C, Guillemin F, et al. Guidelines for the process of cross-cultural adaptation of self-report measures. Spine (Phila Pa 1976) 2000;25:3186-91.

21. Peterson R. A meta-analysis of Cronbach's coefficient alpha. J Consum Res 1994;21:381-91.

22. Husted JA, Cook RJ, Farewell VT, et al. Methods for assessing responsiveness: a critical review and recommendations. J Clin Epidemiol 2000;53:459-68.

23. Fukui M, Chiba K, Kawakami M, et al. Japanese 
Orthopaedic Association Cervical Myelopathy Evaluation Questionnaire: part 3. Determination of reliability. J Orthop Sci 2007;12:321-6.

24. Fukui M, Chiba K, Kawakami M, et al. Japanese Orthopaedic Association Cervical Myelopathy Evaluation Questionnaire (JOACMEQ): part 4. Establishment of equations for severity scores. Subcommittee on low back pain and cervical myelopathy, evaluation of the clinical outcome committee of the Japanese Orthopaedic Association. J Orthop Sci 2008;13:25-31.

25. Wada E, Fukui M, Takahashi K, et al. Japanese orthopaedic association cervical myelopathy evaluation questionnaire (JOACMEQ): Part 5. Determination of responsiveness. J Orthop Sci 2019;24:57-61.

26. Chien A, Lai DM, Cheng CH, et al. Translation, crosscultural adaptation, and validation of a Chinese version of the Japanese Orthopaedic Association Cervical Myelopathy Evaluation Questionnaire. Spine (Phila Pa 1976) 2014;39:963-70.

27. Cheung PWH, Wong CKH, Lau ST, et al. Psychometric Validation of the Adapted Traditional Chinese (Hong Kong) Version of the Japanese Orthopaedic Association Cervical Myelopathy Evaluation Questionnaire (JOACMEQ). Spine (Phila Pa 1976) 2018;43:E242-9.

28. Witayakom W, Paholpak P, Jirarattanaphochai K, et al. Validation of the reliability of the Thai version of the Japanese Orthopaedic Association Cervical Myelopathy Evaluation Questionnaire (JOACMEQ). J Orthop Sci 2016;21:124-7.

29. Azimi P, Rezaei O, Montazeri A. An outcome measure of functionality and quality of life in patients with cervical myelopathy. Iran Red Crescent Med J 2014;16:e8102.

30. Yao M, Li ZJ, Zhu B, et al. Simplified Chinese version of the Japanese Orthopaedic Association Cervical Myelopathy Evaluation Questionnaire: cross-cultural adaptation, reliability, and validity for patients with cervical spondylotic myelopathy. Disabil Rehabil 2020. doi: 10.1080/09638288.2020.1822931. [Epub ahead of print].

31. Zhang W, Zhang X, Li H, et al. Prevalence of lower urinary tract symptoms suggestive of benign prostatic hyperplasia (LUTS/BPH) in China: results from the China Health and Retirement Longitudinal Study. BMJ Open 2019;9:e022792.

32. Martin SA, Haren MT, Marshall VR, et al. Prevalence and factors associated with uncomplicated storage and voiding lower urinary tract symptoms in community-dwelling
Australian men. World J Urol 2011;29:179-84.

33. Zhu Q, Shu H, Dai Z. Effect of pelvic floor dysfunction on sexual function and quality of life in Chinese women of different ages: An observational study. Geriatr Gerontol Int 2019;19:299-304.

34. Liu S, Yang SD, Fan XW, et al. Analyses of effect factors associated with the postoperative dissatisfaction of patients undergoing open-door laminoplasty for cervical OPLL: a retrospective cohort study. J Orthop Surg Res 2019;14:161.

35. Matsunaga S, Sakou T, Taketomi E, et al. Clinical course of patients with ossification of the posterior longitudinal ligament: a minimum 10-year cohort study. J Neurosurg 2004;100:245-8.

36. Nakashima H, Kanemura T, Kanbara S, et al. What Are the Important Predictors of Postoperative Functional Recovery in Patients With Cervical OPLL? Results of a Multivariate Analysis. Global Spine J 2019;9:315-20.

37. Yoshii T, Sakai K, Hirai T, et al. Anterior decompression with fusion versus posterior decompression with fusion for massive cervical ossification of the posterior longitudinal ligament with a $>/=50 \%$ canal occupying ratio: a multicenter retrospective study. Spine J 2016;16:1351-7.

38. Yoshimura N, Nagata K, Muraki S, et al. Prevalence and progression of radiographic ossification of the posterior longitudinal ligament and associated factors in the Japanese population: a 3-year follow-up of the ROAD study. Osteoporos Int 2014;25:1089-98.

39. Lee T, Chacha PB, Khoo J. Ossification of posterior longitudinal ligament of the cervical spine in non-Japanese Asians. Surg Neurol 1991;35:40-4.

40. Inamasu J, Guiot BH, Sachs DC. Ossification of the posterior longitudinal ligament: an update on its biology, epidemiology, and natural history. Neurosurgery 2006;58:1027-39; discussion 1027-39.

(English Language Editors: J. Reynolds and J. Chapnick)

Cite this article as: Li S, Kodama J, Wei L, Wu T, Fujiwara H, Nagamoto Y, Tan LA, Zhao Y, Zhang F, Pan S, Sun Y, Zhou F, Kaito T, Cao P, Wang B, Liu X. Japanese Orthopaedic Association Cervical Myelopathy Evaluation Questionnaire as an outcome measure for ossification of posterior longitudinal ligament patients in East Asia: an investigation of reliability, validity, and responsiveness. Ann Transl Med 2021;9(13):1060 doi: 10.21037/atm-20-8064 